\title{
Numerical Analysis of Large Diameter Bored Pile Installed in Multi Layered Soil: A Case Study of Damietta Port New Grain Silos Project
}

\author{
M. Eid \#, A. Hefny^, T. Sorour!, Y. Zaghloul\$, M. Ezzat ${ }^{\$ *}$ \\ \#Ain Shams University, Department of Geotechnical Engineering, Cairo, Egypt \\ ^United Arab Emirates University, Civil and Env. Eng. Department, UAE \\ !Ain Shams University, Department of Geotechnical Engineering, Cairo, Egypt \\ \$Higher Institute of Engineering, Department of Civil Engineering, Shorouk City, Cairo, Egypt \\ Received 01 Jan 2018, Accepted 01 March 2018, Available online 04 March 2018, Vol.8, No.2 (March/April 2018)
}

\begin{abstract}
A finite element model is established using MIDAS GTS NX 2018 software, in order to simulate the behavior of an instrumented large diameter bored pile, installed in multi layered soil and tested under three different loading and unloading cycles at Damietta Port Grain Silos project site. Modified Mohr-Coulomb constitutive model has been used to define the drained condition for sandy soil layers and undrained condition for clayey soil layers. Necessary soil parameters were determined from extensive laboratory and in-situ soil tests. Numerical results are compared with field loading test measurements and very good agreement is obtained. The effect of dilatancy angle on pile load transfer mechanism was investigated, and results of the study showed important effect for the dilatancy angle on the pile settlement values and the load distribution along the pile shaft. Results obtained also showed that the plastic zone below the base of the pile at failure extended laterally to about seven times the pile diameter and vertically to about 5 times the pile diameter.
\end{abstract}

Keywords: Large diameter bored pile, full scale pile load test, settlement, pile load distribution, finite element, Modified Mohr-Coulomb constitutive model, load transfer mechanism, pile failure, dilatancy angle, end bearing influence zone.

\section{Introduction}

Recently, significant growth is experienced in construction of high-rises buildings, offshore ports, wind power mills, storage silos and many other types of heavy loaded structures. In these cases, large diameter bored piles are attributed to be the most powerful element of deep foundations that can successfully be utilized in different subsurface conditions. They are employed most frequently both to support heavy loads and to minimize settlement (Reese and O'Neill (1999)).

Despite the availability of suggested design equations and interpretation methods for large diameter bored piles, these equations and methods carry various degrees of uncertainty (Tawfik et al. (2009)). Considerable engineering judgment is still necessary for predicting the performance of large diameter piles, and in-situ loading tests will still be desirable to refine initial estimates obtained from the design equations (Rollins (2005)). However, in field

*Corresponding author M. Ezzat (ORCID ID: 0000-0001-7751- 9773) is Assistant Lecturer, Geotechnical Eng., Department of Civil Engineering, Higher Institute of Engineering, Shorouk City, Cairo, Egypt, DOI: https://doi.org/10.14741/ijcet/v.8.2.4 tests, loading of large diameter bored piles till reaching apparent failure is practically seldom. This may be attributed to the significant amount of pile settlement that is usually required for the full mobilization of the pile shaft and base resistances (Meyerhof (1986); Reese and O'Neill; and Mullins et al. (2000)). Huge test loads and hence, high-capacity reaction systems should be used to accomplish the required enormous settlements. Thus, the targeted failure load may not always be practical to achieve. This may be the reason that the measured pile load-settlement curves for large diameter bored piles usually don't show an apparent failure point.

Numerical studies related to axially loaded single piles were discussed by many authors, e.g. Lee and Salgado (1999), Baars and Niekerk (1999), and Wehnert et al. (2004). In this paper, a finite element model is used to simulate the behavior of an instrumented large diameter bored pile under cycles of loading and unloading in a field loading test.

\section{Case study}

Figure 1 illustrates Damietta Port Grain Silos project site layout. Extensive site investigations showed that the soil at the site is characterized by successive layers of sand and clay. 


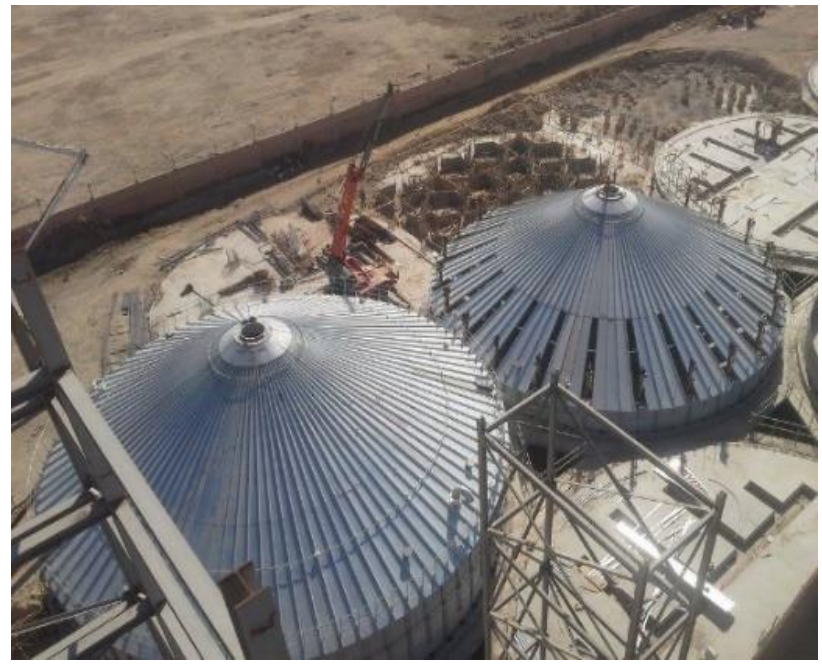

Fig.1 Damietta Port Grain Silos site layout

Figure 2 shows the soil layers profile at the site. Description of the encountered soil layers and their properties are presented by Eid et al. (2018).

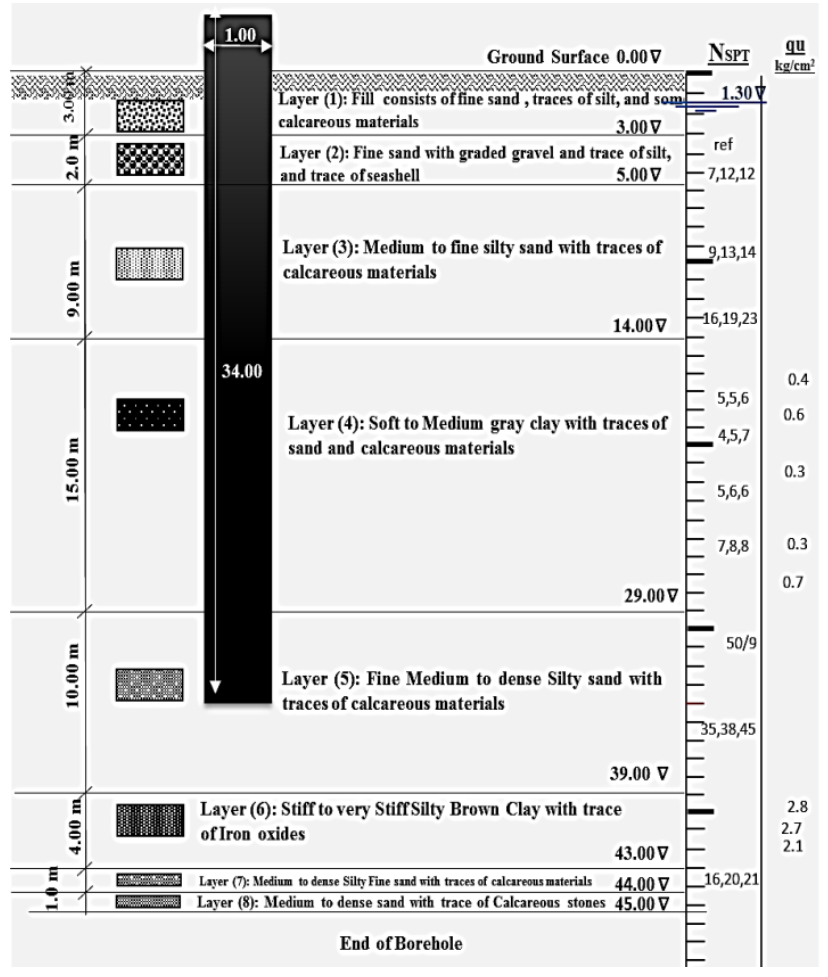

Fig.2 Soil Profile at location of the non-working instrumented pile

Because of the large loads acting on these silos due to their high capacities, and in order to optimize the number of required piles, it was decided to use large diameter bored piles with a diameter of $1.0 \mathrm{~m}$ and length of $34.0 \mathrm{~m}$.

According to the Egyptian code of deep foundations (ECP202/4 (2005)), two non-working piles were installed to be tested under load of $9000 \mathrm{kN}$ (three times the design load) in order to determine pile ultimate capacity. One of these two piles, was chosen to be instrumented in order to investigate pile load transfer mechanism. The pile load test field measurements were obtained in the form of load settlement, and the load distribution curves for different loading steps. Details of instrumentations and test results are also provided by Eid et al. (2018).

\section{Finite element model}

\subsection{Geometry and boundary conditions}

Two-dimensional axisymmetric finite element model is established using MIDAS GTS NX 2018. Based on a sensitivity analysis performed, a model height of $68 \mathrm{~m}$ and width of $34 \mathrm{~m}$ was adopted in the analysis (Figure 3 ). The analysis showed that the positions of the model boundaries do not affect the obtained stresses and displacement around the pile.

The outer boundaries of the model were supported to avoid instability (singularity) of finite element model. The right and left edges were considered fixed in the horizontal-direction, and free to move in the vertical-direction. The bottom boundary was considered fixed in both the horizontal and vertical directions, and the top boundary was taken free.

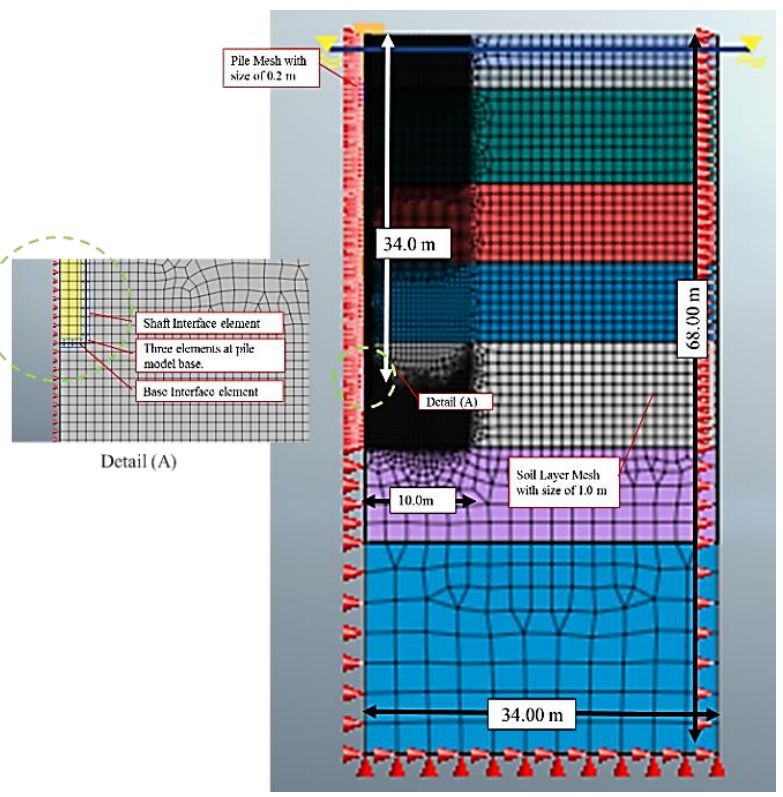

Fig.3 Finite element model geometry dimensions and boundary conditions

\subsection{Soil model properties}

Quadratic elements (20-noded) were used to represent the soil. Three different sizes were used to investigate the sensitivity of the soil mesh refinement and its effect on the results. Good enhancement was observed in stress and settlement results when fine mesh (with size of less than $0.2 \mathrm{~m}$ ) was used. However, analysis time significantly increased. These attempts results are not shown here due to the lack of space. As a compromise solution, a zone of very fine mesh with 
size of $0.2 \mathrm{~m}$ was considered around and below the pile $(10 \mathrm{~m} \times 40 \mathrm{~m})$. Gradually, soil mesh size is increased to be $1.0 \mathrm{~m}$ at boundaries locations. As shown in Figure 3, few triangular mesh elements were automatically generated due to the aspect ratio of the model geometry.
Modified Mohr-Coulomb model Groen (1995) is used to define isotropic soil undrained condition for clayey soil layers and drained condition for sandy soil layers. According to field study (Eid et al., 2018), in situ and laboratory soil tests were carried out to determine the soil properties. The mechanical properties of the eight soil layers encountered at the site are given in Table 1.

Table 1 Soil layers engineering parameters
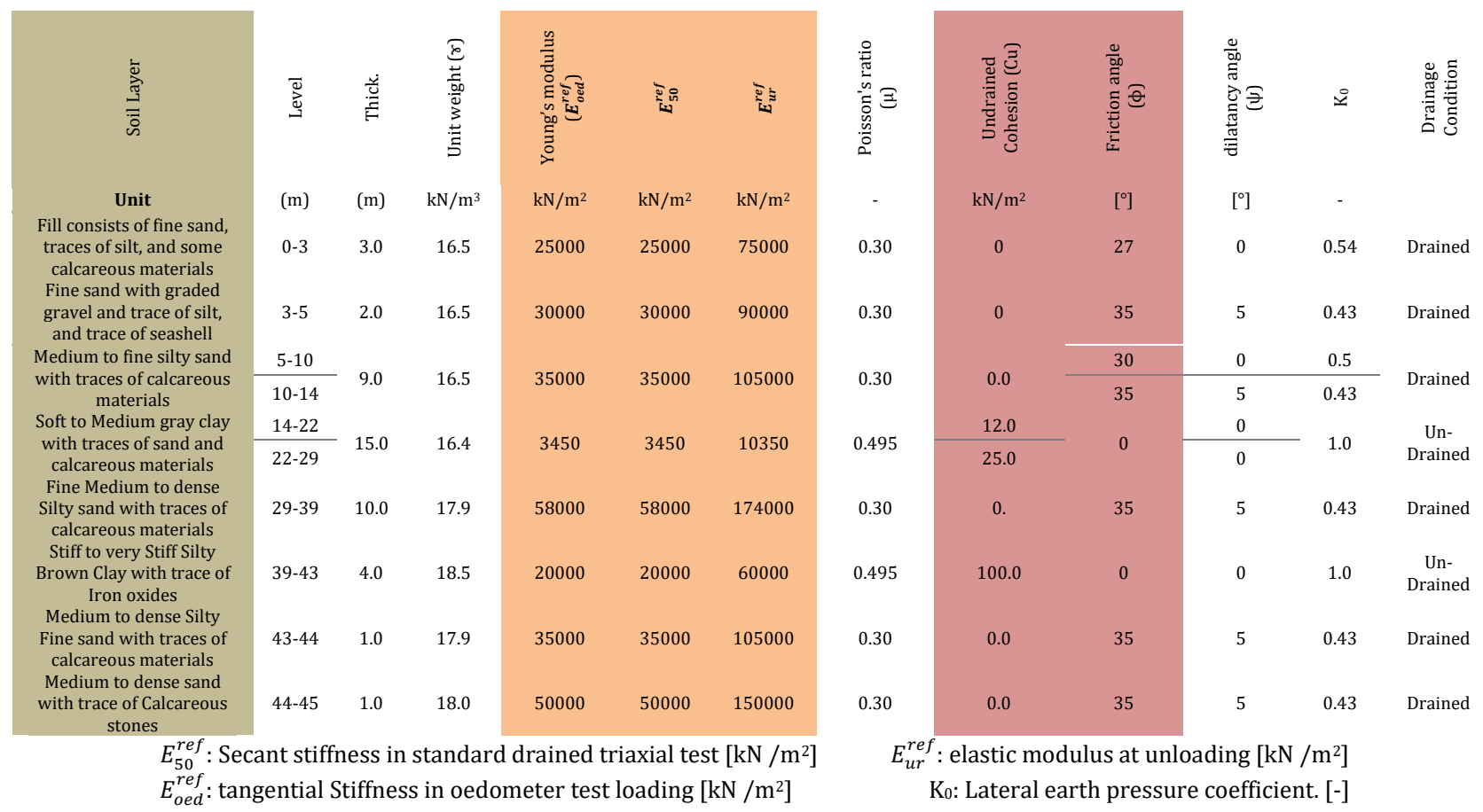

The Modified Mohr Coulomb model is a double hardening model where a yield surface represents the shear yielding up to Mohr Coulomb failure surface and another surface represents compression yielding.

This model requires the input of three elasticity moduli, $E_{\text {oed }}^{r e f}, E_{50}^{r e f}$ and $E_{u r}^{r e f}$. The parameter $E_{50}^{r e f}$ is the confining stress dependent stiffness modulus for primary loading. $E_{50}^{r e f}$ and it is used instead of the initial modulus $E_{i}$ for small strain. For unloading and reloading stress paths, another stress-dependent stiffness modulus $E_{u r}^{r e f}$ is used. In many practical cases it is appropriate to set $E_{u r}^{r e f}$ equal to three times of $E_{50}^{r e f}$, and to set $E_{\text {oed }}^{\text {ref }}$ equal to $E_{50}^{\text {ref }}$, value (Teshome, 2011).

For soil layers having internal angle of friction higher than $30^{\circ}$, the dilatancy angle usually estimated to be equal $\psi=\varphi-30^{\circ}$. The effect of dilatancy on the obtained results is investigated in Section 5.3.

Kulhawy (1991) indicated that the coefficient of lateral earth pressure $\mathrm{K}_{0}$ is the most important and difficult parameter to determine. A simplified relationship to determine $\mathrm{K}_{0}$ based on soil friction angle $(\varnothing)$ and the over consolidation ratio (OCR) is given by Equation 1 (Mayne and Kulhawy, 1990). In this study, OCR was estimated to be equal 1.0, based on geologic and construction history at site location. The calculated values of $\mathrm{K}_{0}$ using Eq. 1 are summarized in Table 1.

$K_{0}=(1-\sin \emptyset)$ OCR $\sin \varnothing$

\subsection{Pile model properties}

Two-dimensional quadratic mesh elements (20-noded) are used to represent the pile. At least two or three elements at the pile base are required to get rid of the mesh dependency effect on pile bearing resistance (Wehnert and Vermeer). Consequently, pile mesh size is taken as $0.167 \mathrm{~m}$. Elastic isotropic concrete material is used to define the pile mesh material. Characteristic compressive strength $(f c u)$ of $350 \mathrm{~kg} / \mathrm{cm}^{2}$ was obtained in field after 28 curing days. Based upon, pile properties are taken as given in Table 2 .

Table 2 Large diameter pile structural parameters

\begin{tabular}{|c|c|c|}
\hline Pile model parameters & Unit & \\
\hline Pile Diameter $(\mathrm{D})$ & $\mathrm{m}$ & 1.00 \\
\hline Pile Length $(\mathrm{L})$ & $\mathrm{m}$ & 34.0 \\
\hline Young's Modulus $\left(\mathrm{E}_{\text {elastic }}\right)$ & $\mathrm{kN} / \mathrm{m}^{2}$ & $26^{*} 10^{6}$ \\
\hline Poisson's Ratio $(\mu)$ & {$[-]$} & 0.20 \\
\hline Unit weight $(\gamma)$ & $\mathrm{kN} / \mathrm{m}^{3}$ & 25.0 \\
\hline
\end{tabular}




\subsection{Interface elements properties}

Interface elements allow for differential displacements between the node pairs (slipping and gapping), as it interacts with two elastic-perfectly plastic springs. One spring models gap while the other models slip. Slipping and gapping displacement at the interface is described with Equations 2 and 3 (GTS NX).

gap displacement $=\frac{\sigma}{K_{N}}=\frac{\sigma . t_{i}}{\text { Eoed }_{i}}$

slip displacement $=\frac{\tau}{K_{S}}=\frac{\tau \cdot t_{i}}{G_{i}}$

Where,

$\mathrm{G}_{\mathrm{i}}$ : shear modulus $\left[\mathrm{kN} / \mathrm{m}^{2}\right]$.

$\mathrm{E}_{\text {oedi: }}$ compression modulus $\left[\mathrm{kN} / \mathrm{m}^{2}\right]$.

$t_{i}$ : virtual thickness of the interface factor (ranging from 0.01 to 0.1 ) [-].

$\mathrm{K}_{\mathrm{N}}$ : interface normal stiffness $\left[\mathrm{kN} / \mathrm{m}^{3}\right]$.

$\mathrm{K}_{\mathrm{s}}$ : interface shear stiffness $\left[\mathrm{kN} / \mathrm{m}^{3}\right]$.

The Coulomb criterion is used to distinguish between elastic behavior, where small displacements can occur within the interface, and plastic interface behavior when permanent slip may occur. Furthermore, shear strength parameters of the interface elements are linked to the strength of the neighbor soil layers through a strength reduction factor (R). as given by Equation (4).

$\mathrm{C}_{\mathrm{i}}=\mathrm{R}^{*} \mathrm{C}_{\text {soil }}$

$\tan \varphi_{\mathrm{i}}=\mathrm{R}^{*} \tan \varphi_{\text {soil }}$

$\psi_{\mathrm{i}}=0^{\circ}$ for $\mathrm{R}<1$, otherwise $\psi_{\mathrm{i}}=\psi_{\text {soil }}$

Where;

$\varphi_{\mathrm{i}}$ : Angle of friction. $\left[^{\circ}\right]$

$\mathrm{C}_{\mathrm{i}}$ : Effective adhesion. [kN/ $\left./ \mathrm{m}^{2}\right]$

$\psi_{\mathrm{i}}$ Angle of dilatancy. $\left[^{\circ}\right]$

Several analysis attempts were performed, and good agreement was obtained between finite element results and field measured pile settlement values, when the shear strength reduction factor (R) for interface elements was taken as 1.00 .

\section{Stages of Analysis}

The analysis is divided into three stages, the first stage represents the initial stresses in the soil before the pile implementation. The second stage starts by changing the pile volume to concrete material instead of soil material. At this stage, rigid interface element is used to connect pile and soil mesh elements in order to avoid any numerical instability (singularity). Pile own weight is considered at this stage. The resulted displacement of the first and second stages of analysis are cleared in order to start account pile settlement due to loading only. In the third stage of analysis, interface elements are activated with deactivation of the rigid interface. In addition, load of $9000 \mathrm{kN}$ is applied on the pile head using incremental loading and unloading steps to simulate the pile loading process with same field loading test steps. Table 3 presents the values of load increments.

Table 3 Loading and unloading increments

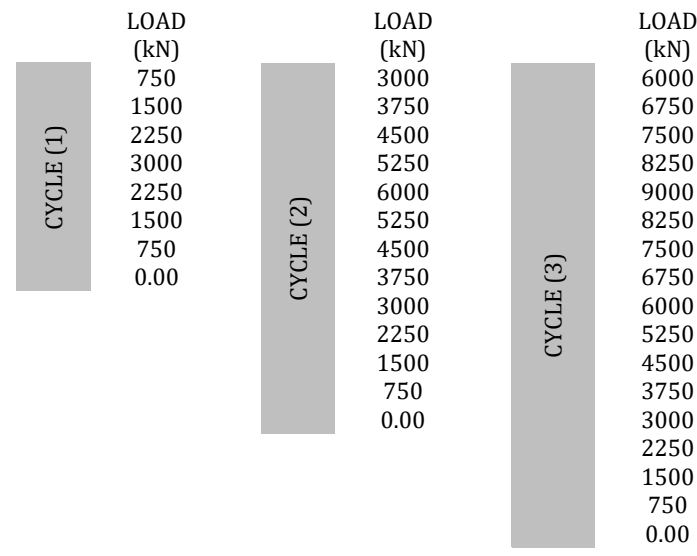

\section{Finite Element Model Verification}

Thirty-eight loading/unloading steps were used in the numerical model to simulate the loading increments applied on the pile during the test (Table 3). Simulation results are given in this section.

\subsection{Pile head settlement}

The obtained pile settlement values at the pile head using the numerical analysis are compared with field measured values, in order to examine the accuracy of finite element model results. Figure 4 shows a comparison between field measurement and finite element results of pile head settlement $(\mathrm{mm})$ at each loading and unloading increment.

It can be seen from Figure 4 that very good agreement is obtained between finite element results and field measurements.

Besides, at the first unloading cycle, the pile rebounded to almost its initial condition which is in consistent with Tomlinson (1995) findings that at lower applied loads soil acts as an elastic material. After the removal of second cycle load, about $2.00 \mathrm{~mm}$ permanent settlement is recorded, and about 12.00 $\mathrm{mm}$ of permanent settlement is observed after the third cycle load removal. This can be attributed to the increase of the plastic deformation as the applied load increases. 


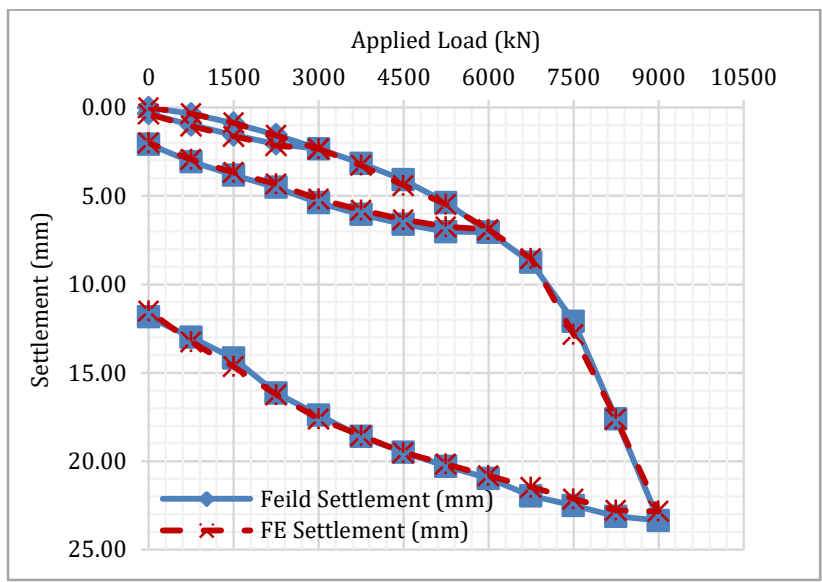

Fig.4 Comparison between field measurements and finite element results of pile settlement under loading and unloading cycles

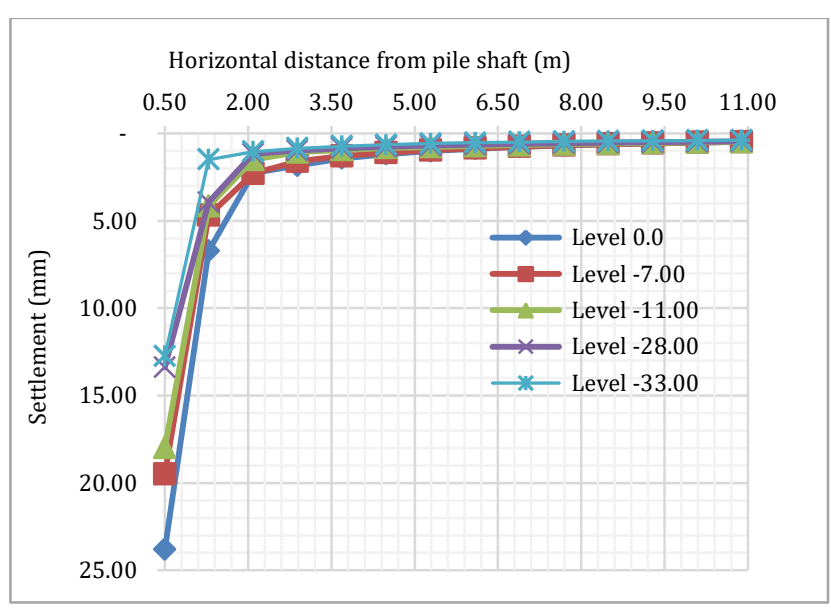

Fig.5 vertical displacement distribution on horizontal sections at levels of $0.00,-7.0,-11.0,-28.0$ and $-33.0 \mathrm{~m}$ under applied load of $9000 \mathrm{kN}$

\subsection{Surrounding soil movement}

Surrounding soil settlement results were also obtained from finite element analysis under load of $9000 \mathrm{kN}$, using horizontal sections passing through soil, and interface elements at levels of $0.00,-7.00,-11.00$, $28.00 \mathrm{~m}$, and $-33.00 \mathrm{~m}$. Figure 4 highlights that the highest settlement value occurred at pile head level 0.0 $\mathrm{m}$. While, the smallest settlement value was obtained at pile base level $-33.00 \mathrm{~m}$. The increase of pile settlement from the base to the head is attributed to the elastic compression of the pile $(10 \mathrm{~mm})$.

Figure 5 also demonstrates that the maximum soil settlement occurs at the interface with pile, and the settlement values decreases as the horizontal distance increases. The rate of decrease of settlement is large in the soil surrounding the pile with radius of about 2D (twice pile diameter) from the center of pile. In this zone the settlement decreased to about $10 \%$ of its maximum value.

\subsection{Pile load transfer mechanism}

Two finite element analyses with different dilatancy angles for the granular soil layers were carried out in order to investigate the effect of dilatancy angle on pile load transfer mechanism. In the first analysis, dilatancy angle of five degrees $\left(\psi=5^{0}\right)$ was employed for granular soils that have friction angle higher than thirty degrees, as noted before in Section (3.2). Also, dilatancy of zero degree $\left(\psi=0^{0}\right)$ was taken in the second analysis.

Finite element results of pile load distribution under the three cycles loads of $3000 \mathrm{kN}, 6000 \mathrm{kN}$ and $9000 \mathrm{kN}$ are compared with the in-situ measurements at the same corresponding levels and loads, and the results of the comparison are shown in Figure 6.

Generally, it can be seen that considering a dilatancy angle led to a better agreement with field measurements. Also, Figure 6 indicates that at applied load of $3000 \mathrm{kN}$, both of the two analyses gave almost the same result of pile load distribution along pile shaft depth. In contrast, under higher applied loads of 6000 $\mathrm{kN}$ and $9000 \mathrm{kN}$, difference is observed between field measurements and $\left(\psi=0^{0}\right)$ attempt results. This difference ranging from about $10 \%$ near the head to about $50 \%$ near the pile base.

It was also noted that, in $\left(\psi=0^{0}\right)$ analysis pile settlement increased to about $31 \mathrm{~mm}$ under load of $9000 \mathrm{kN}$ instead of about $24 \mathrm{~mm}$ as obtained using $\left(\psi=5^{0}\right)$ and as field measurements. Therefore, it can be concluded that using small dilatancy angle for sand $(\psi$ $=\varphi-30^{\circ}$ ) in numerical analysis leads to better agreement with in situ measurements, in both of pile load distribution and pile settlement. 


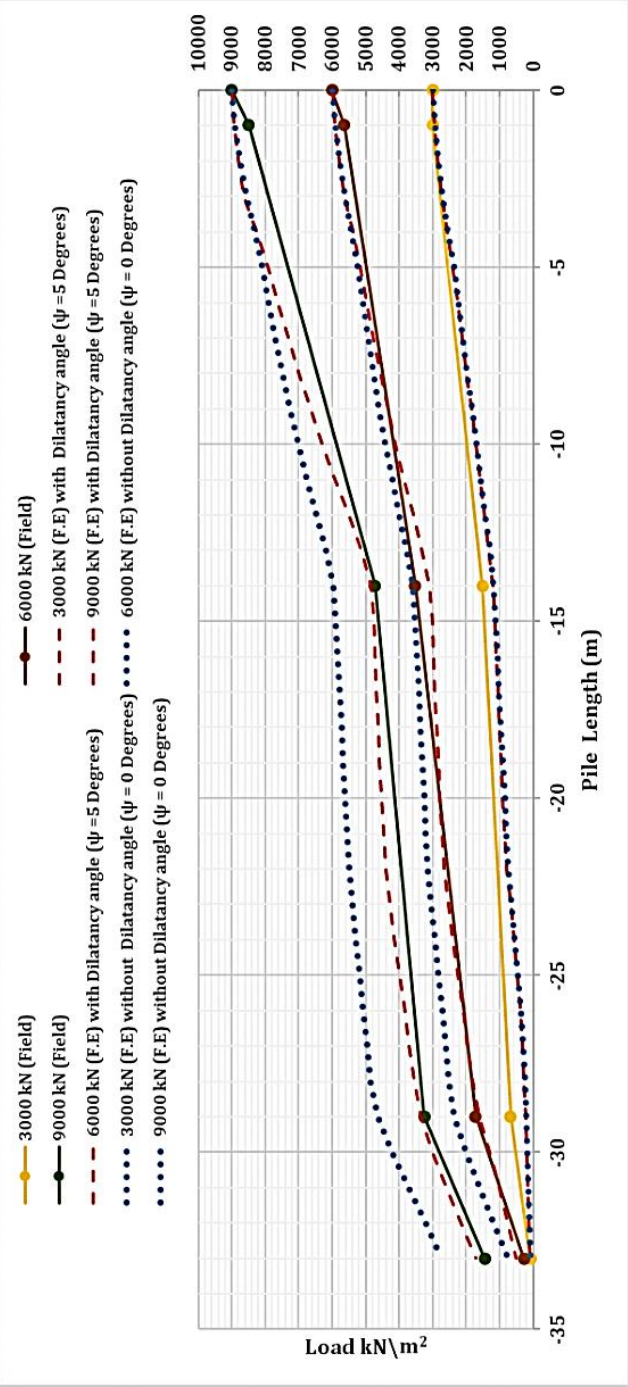

Fig.6 Comparison between in-situ pile load distribution along pile shaft and finite element results under main loading cycles $(3000,6000$ and $9000 \mathrm{kN}$ )

\subsubsection{Skin friction}

Interface elements tangential stresses in vertical direction were obtained at each load increment, along interface depth. The relations between interface tangential stresses and depth below ground surface are shown in Figures 7(a) and (b) for both analyses with dilatancy angle $(\psi)$ of $5^{0}$ and $0^{0}$ respectively. The tangential stresses represent the soil mobilized unit skin resistance at each load increment and along pile length. To assess the obtained side resistance values, the finite element results were compared with the Kulhawy (1989) and Reese and O'Neill methods.

Kulhawy method is based on basic soil mechanics principles with allowance for variations in soil properties based on construction procedures. The unit side resistance is given by Equation (5), where $K$ is the coefficient of lateral earth pressure, $\sigma_{\mathrm{z}}$ is the vertical effective stress, $C_{a}$ is the cohesive soil adhesion, and $\delta$ is the soil external friction angle.

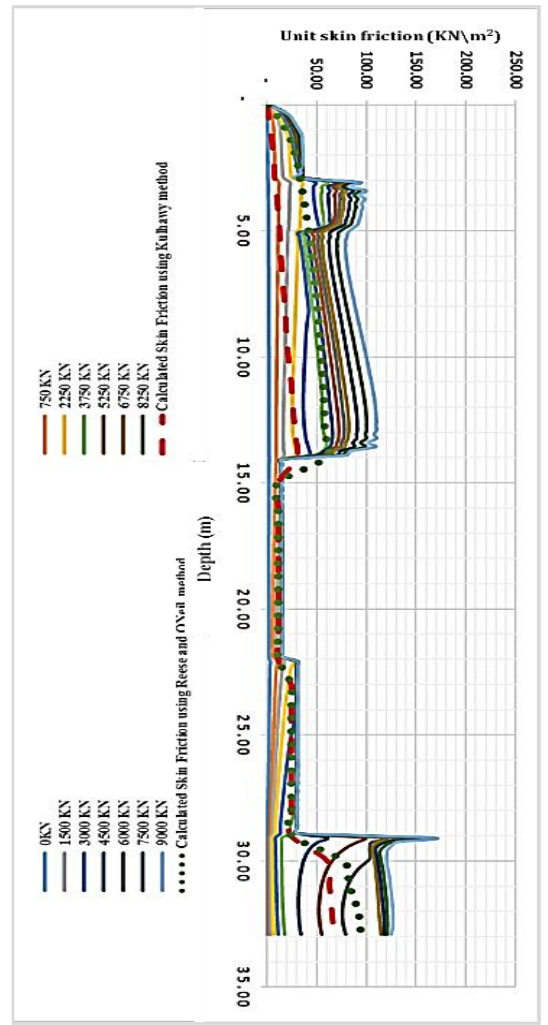

Fig.7(a) Calculated unit skin friction using finite element $\left(\psi=5^{0}\right)$,Kulhawy, and $0^{\prime}$ Neill methods

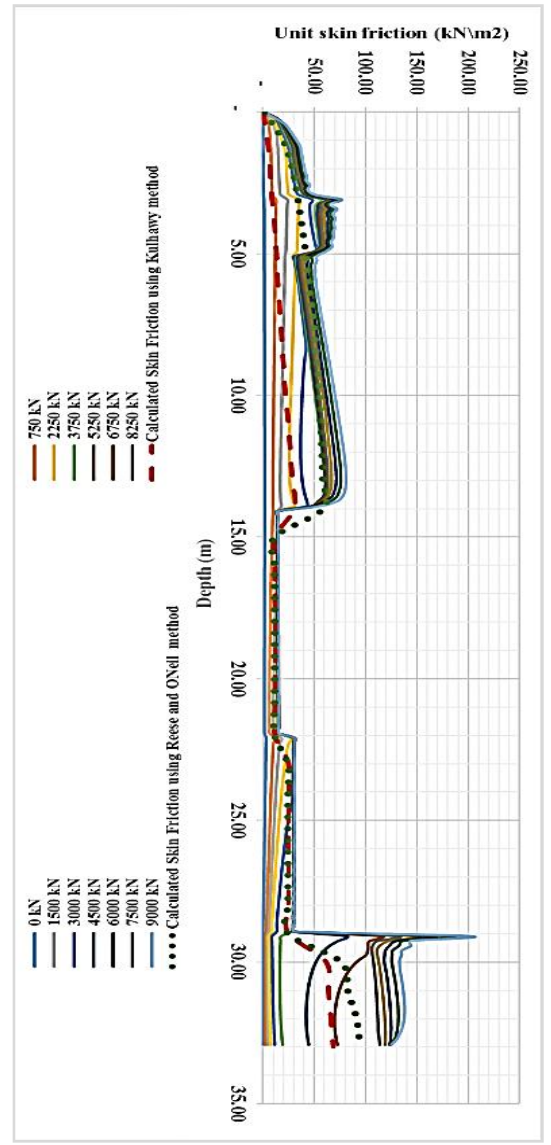

Fig.7(b) Calculated unit skin friction using finite element $\left(\psi=0^{0}\right)$, Kulhawy , and $0^{\prime}$ Neill methods 
$f_{s}=\sigma_{z} K \tan \delta+C_{a}$

Kulhawy suggested that $(\delta)$ can be expressed as a fraction of the soil friction angle, $\emptyset$. For cast-in-place concrete and good construction techniques, a rough interface develops, giving $\delta / \varnothing$ equal to 1.0 . With poor slurry construction this ratio could be 0.8 or lower. For calculations in this study, $\delta / \varnothing$ was assumed to be 1.0 , similar to the considered value of the interface reduction factor $(\mathrm{R})$ in finite element analysis.

By examining several hundred load tests, Kulhawy found that $K / K_{0}$ varies between 0.67 and 1 and is a function of the construction method. For dry construction, minimal sidewall disturbance, and prompt concreting, the soil disturbance is minimized and $\mathrm{K} / \mathrm{K}_{0}$ approaches 1 . In this study, $K / K_{0}$ was taken equal to 1.0. The unit skin resistance was calculated using Kulhawy and compared with those obtained using finite element method at each loading increment, as shown in Figures 7 (a) and (b).

The Reese and O'Neill empirical method is based on a set of 41 drilled shaft load tests. The ultimate unit side resistance in sand is given by Equation 6, where, $\sigma_{\mathrm{z}}$ is the vertical effective stress in soil at depth $\mathrm{z}$ and $\beta$ is side friction ceofficient $\left(\beta=1.5-0.245 \mathrm{z}^{0.5}\right)$.

$f_{s}=\beta \sigma_{\mathrm{z}}$

O'Neill et al. (1996) observed increased skin resistance as a result of interface roughness for shafts in intermediate geomaterials. The observed roughness of the interface between the granular soil and the concrete shaft would also be expected to cause increased dilation leading to increase in the lateral pressure during shearing. Although the material types may be different, the mechanisms leading to increased lateral pressure appear to be comparable. Unit skin resistance is recalculated using $0^{\prime}$ Neill et al. [19] method and also compared with those obtained using Kulhawy, and finite element $\left(\psi=5^{0}\right.$ and $\left.0^{\circ}\right)$ methods, as shown in Figures $7(\mathrm{a})$ and (b).

Figures $7(a)$ and (b), demonstrates that for the three methods, unit skin resistance values change as soil layers change depending on each layer's shear strength parameters. Also,the unit skin resistance increases as depth increases in sand layers, while remains constant along the depth of the clay layer and equals the undrained cohesion values (after load of $4500 \mathrm{kN}$ ) at different levels of clay layer. Futhermore, good agreement is obtained between Kulhawy and finite element methods results of skin resistance only from level $-14.0 \mathrm{~m}$ to $-29.0 \mathrm{~m}$ (clay layer). However, finite element results are much higher than those obtained by Kulhawy method at upper and lower sand layers.

It can be seen from Fig 7(a) that obtained skin friction values from O'Neill method is greater than those obtained by Kulhawy method. Also, an obvious increase is noticed in mobilized unit skin resistance results of the first analysis $\left(\psi=5^{0}\right)$ compared to those obtained using $\mathrm{O}^{\prime} \mathrm{Neill}$ method for both layers that have friction angle higher than $30^{\circ}\left(\psi=5^{\circ}\right)$.
In contract, as shown in Figure $7(\mathrm{~b})$ very good agreement is obtained between mobilized unit skin resistance results of the second analysis attempt $\left(\psi=0^{0}\right)$ and those obtained using $0^{\prime}$ Neill method.

As noted before in Section 5.3, good agreement was obtained between field measurements and numerical results, when dilatancy angel of five degrees is taken, which indicates that field measurement of unit skin resistance is higher than the obtained values from Kulhawy and O'Neill methods. This finding is in agreement with Rollins findings.

Rollins studied drilled shaft friction resistance through 28 axial tension (uplift) tests performed at eight different sites in Northern Utah and determined the values of $\mathrm{K}$ for gravelly and granular sand. $\mathrm{He}$ observed that higher $\mathrm{K}$ values was obtained from field test measurements than values calculated using Kulhawy or O'Niell methods. This was explained by the increase in lateral pressure during shearing due to dilation of granular soils. Near the ground surface with low confining pressure, the soil would dilate during shearing that causes a significant increase in lateral pressure. At greater depth the increase in lateral pressure is less severe because of reduced change of dilation under a higher confining (or overburden) pressure.

\subsubsection{Pile side and base resistances}

Pile bearing resistance is calculated by integration of bearing stress at the pile base. The obtained bearing load was deducted from total applied load in order to determine pile total friction load at each loading increment. Relation between pile settlement, pile side and base resistances under every loading increments was obtained and compared with field values in Figure 8. Excellent agreement is obtained between finite element results and in-situ measurements.

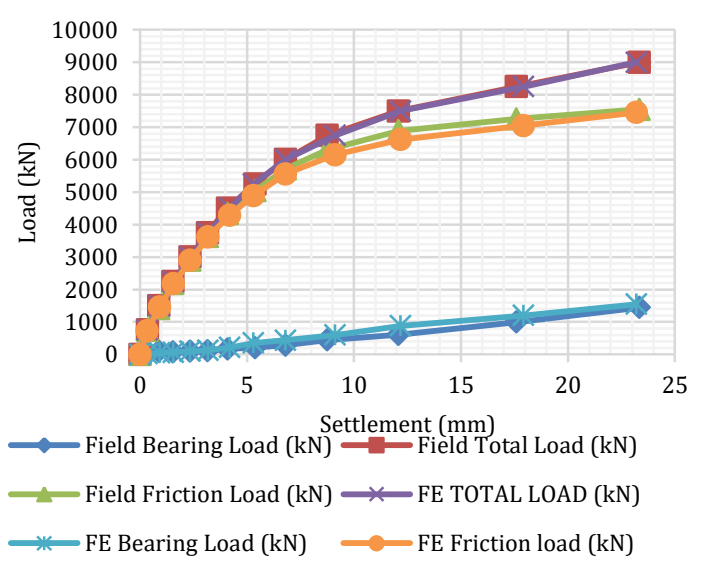

Fig.8 Comparison between field and Finite element pile load transfer mechanisms

At the last load increment (9000 kN), the pile carried about $7452 \mathrm{kN}$ ( $83 \%$ of total applied load) by friction resistance and about $1547 \mathrm{kN}$ (17\% of total applied 
load) by bearing resistance. The observed increase in pile bearing and friction resistances with pile loading could be interpreted as pile didn't achieve its ultimate capacity and still can carry loads larger than $9000 \mathrm{kN}$.

\section{Ultimate capacity of the large diameter bored pile}

According to Egyptian code of deep foundation (ECP202/4), if field loading test results did not show apparent failure value, the pile ultimate load can be estimated as the average values that are obtained from modified Chin (1970) and Hansen (1963) methods. According to field study (Eid et al., 2018). the two mentioned methods were applied, and the average of their results was obtained as $10059 \mathrm{kN}$.

The finite element model has been utilized under higher applied load than $9000 \mathrm{kN}$. The maximum load where convergence can be obtained in the numerical model is $10500 \mathrm{kN}$. This is considered as the failure load.

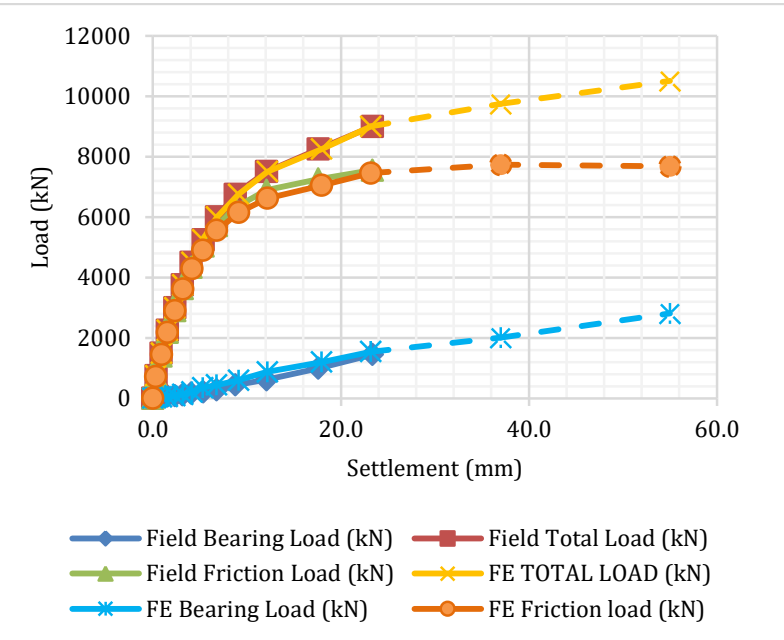

Fig.9 pile load settlement, friction and bearing resistances under determined ultimate load using finite element method

Figure 9, presents the relation between pile settlement, pile side and base resistances that are obtained at the end of this analysis attempt. Large increase in pile settlement is observed under the $10500 \mathrm{kN}$ load (55.42 $\mathrm{mm}$ ). This is more than twice pile settlement value at load increment of $9000 \mathrm{kN}$. Fundamental to note that, pile friction resistance tend to slightly decrease after load of $9750 \mathrm{kN}$. Also, obvious increase in pile bearing resistance was noted at the ultimate load of $10500 \mathrm{kN}$. The obtained ultimate capacity from numerical analysis are compared with the average load estimated from modified Chin and Hansen methods, as shown in Figure 10.

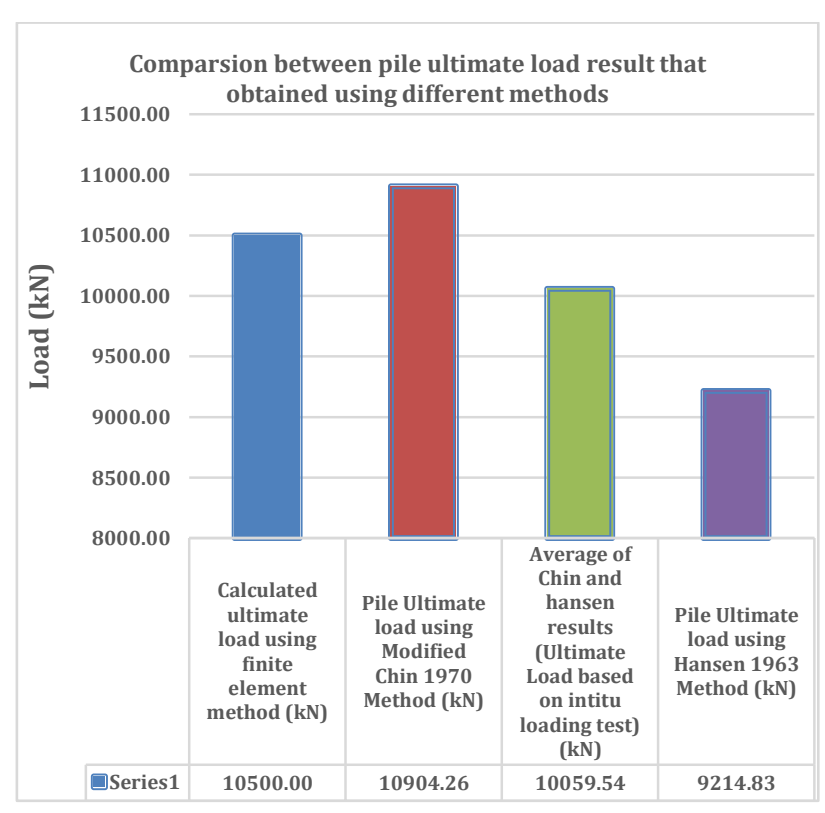

Fig.10 Comparison between pile ultimate load results that are obtained using different methods

It can be seen from Figure 10 that the calculated ultimate load using modified Chin (10904 kN) is higher than ultimate load that is calculated using Hansen $(9215 \mathrm{kN})$ with a difference of about $18 \%$. Also, Pile ultimate load calculated from numerical analysis $(10500 \mathrm{kN})$ is nearly equal to the average load estimated from Chin and Hansen methods (10059 kN).

\section{Size of Failure zone below pile base}

Figures 11 and 12 present the plastic points that are formed around pile interface and under pile base at applied load of $9000 \mathrm{kN}$ and $10500 \mathrm{kN}$ (failure load) respectively. Plastic bulb diameter was measured to be about five times of pile diameter (5D) under $9000 \mathrm{kN}$ and is expanded to seven times of pile diameter (7D) under the failure load $(10500 \mathrm{kN})$.

Figure 11 illustrates that plastic zone extended with length of $3.08 \mathrm{~m}$ (3D) below the pile base level under load of $9000 \mathrm{kN}$. At failure load $(10500 \mathrm{kN})$ the depth of plastic zone increased to about five times pile diameter (5D) below the pile base (Figure 12).

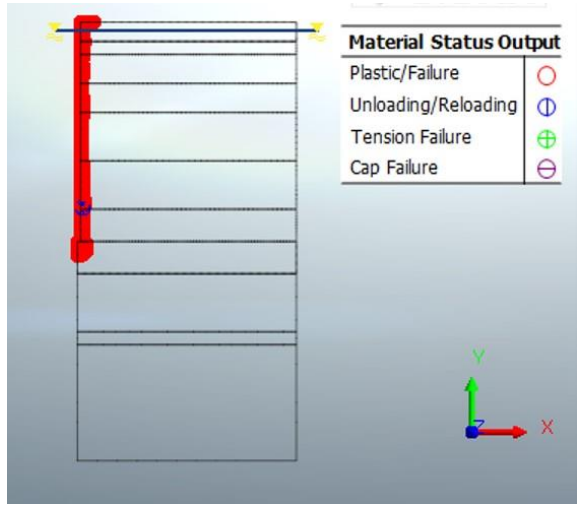

Fig.11 Formation of plastic points under a load of 9000 $\mathrm{kN}$ according to finite element analysis results 


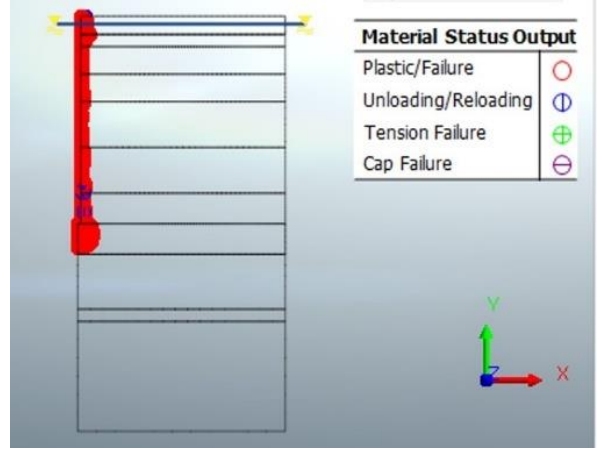

Fig.12 Formation plastic points under a load of $10500 \mathrm{kN}$ (failure load) according to finite element analysis results

\section{Conclusions}

From the analytical and numerical studies performed, the following conclusions can be drawn:

- Very good agreement is obtained between numerical results and field measurements for both of pile load distribution and pile settlement values under each of the three loading and unloading cycles.

- Dilatancy angle has an important effect on the load distribution along the large diameter bored pile length.

- Numerical result of unit skin friction is compared with calculated side friction using Kulhawy (1989) and O'Neil (1996) methods. Results from O'Neil method are nearer to the field measurements and the numerical results than those calculated by Kulhawy method.

- Finite element results are consistent with field measurements of Damietta instrumented pile bearing and friction resistances. As, at load of 9000 $\mathrm{kN}$ about $83 \%$ of the applied load was transferred by friction and about $17 \%$ of total load was carried by bearing.

- At failure load of $10500 \mathrm{kN}$, pile settlement is increased more than twice pile settlement value at $9000 \mathrm{kN}$. This settlement was also more than five times of pile diameter $(5.5 \% \mathrm{D})$.

- $\quad$ Pile friction resistance tends to slightly decrease at the failure load $(10500 \mathrm{kN})$ obtained from numerical analysis. Also, an obvious increase in pile bearing resistance was noted at this load.

- The plastic bulb below the base of the pile extended at failure to a depth of about five times the diameter of the pile (5D).

- Diameter of the plastic zone at failure is about seven times of the pile diameter (7D).

- Pile ultimate load calculated from numerical analysis is nearly equal to the average load estimated from Chin (1970) and Hansen (1963) methods.

\section{References}

O'Neill, M. W., and Reese, R. C. (1999). Drilled shaft: construction procedures and design methods. Federal Highway Administration, Washington, D.C.
F.M. El-Nahhas, Y.M. El-Mossallamy, and M.M. Tawfik, 2009, Assessment of the skin friction of large diameter bored piles in sand, Proceedings of the 17th International Conference on Soil Mechanics and Geotechnical Engineering.

Rollins K.M., Clayton R.J., Mikesell R.C., and Blaise B.C. (2005), Drilled Shaft Side Friction in Gravelly Soils. Journal of Geotechnical and Geoenvironmental Engineering, Vol. 131, No. 8, pp. 987-1003.

Meyerhof, G. G. (1986). Theory and Practice of Pile Foundations. In proceedings of the International Conference on Deep Foundations, Beijing, vol. 2, pp. 177186.

Mullins, G.; Dapp, S.; and Lai, P. (2000). Pressure Grouting Drilled Shaft Tips in Sand. New technological and design developments in deep foundations, N. D. Dennis, R. Castelli, and M. W. O'Neill, eds., ASCE, Reston.

Lee, J. H., and Salgado, R. (1999). Determination of Pile Base Resistance in Sands. Journal of Geotechnical and Geoenvironmental Eng., ASCE, vol. 125, no. 8, pp. 673683.

Baars, S. v. \& Niekerk, W. v. (1999). Numerical modelling of tension piles. In International Symposium on Beyond 2000 in Computational Geotechnics, pp. 237-246.

Wehnert, M., and Vermeer, P. A. (2004). Numerical Analyses of Load Tests on Bored Piles. Numerical Models in Geomechanics. NUMOG 9th. Ottawa, Canada.

M. Eid, A. Hefny et al., 2018. Full-Scale Well Instrumented Large Diameter Bored Pile Load Test in Multi Layered Soil: A Case Study of Damietta Port New Grain Silos Project. International Journal of Current Engineering and Technology. Jan/Feb Issue.

ECP 202/4. 2005. Egyptian code for soil mechanics - design and construction of foundations. Part 4, Deep foundations. The Housing and Building Research Center (HBRC), Cairo, Egypt.

GROEN, A. E. Elastoplastic Modelling of Sand Using a Conventional Model. Tech. Rep. 03.21.0.31. 34/35, Delft University of Technology, 1995.

GROEN, A. E. Two Elastoplastic Models for the Behaviour of Soils. Tech. Rep. 03.21.0.31.12, Delft University of Technology, 1995.

Fitsum Teshome \& Araz Ismail, 2011 Analysis of deformations in soft clay due to unloading. Master's Thesis, Department of Civil and Environmental Engineering Division of GeoEngineering, Chalmers Uni.

MIDAS GTS NX user manual, Analysis Reference chapter 4 materials, Section 2. Plastic Material Properties.

Kulhawy, F. H. 1991. Drilled shaft foundations. Foundation engineering handbook, 2nd Ed., H. Y. Fang, ed., Van Nostrand-Reinhold, New York.

Kulhawy, F. H., and Mayne, P. W. (1990), Manual on estimating soil properties for foundation design. Rep. No. EPRI EL-6800, Electric Power Research Institute, Palo Alto, Calif. 2-25.

Tomlinson, M.J. (1995). Foundation design and construction practice. 5th Ed., Chapman and Hall.

Kulhawy, F. H., and Hirany, A. 1989. Interpretation of load tests on drilled shafts, Part 2: Axial uplift. Proc., Foundation Engineering, ASCE, New York, Vol. 2, 1150-1159.

O'Neill, M. W., Townsend, F. C., Hassan, K. M., Buller, A., and Chan, P. S. 1996. Load transfer for drilled shafts in intermediate geomaterials. Pub. No. FHWA-RD-95-172, Dept. of Transportation, Washington, D.C, 184-184.

Chin, F. K., (1970). Estimation of the ultimate load of piles from tests not carried to failure. Proc., 2nd. South-East Asian Conf. on Soil Eng., Singapore, pp.81-90.

Hansen, J. B., (1963). Discussion on hyperbolic stress-strain response in cohesive soils. ASCE, Vol. 89, SM4, pp. 241-242. 